\title{
OF THE WORDS CHARACTER AND PERSONALITY
}

\author{
WILLIAM McDOUGALL \\ Duke University, N. C.
}

The present number of this new quarterly is of happy augury; for it is to appear in both the German and the English languages. It thus marks a new period of closer international coöperation in things of the mind. The Editor, having chosen the word 'Charakter' as the German title, has been confronted with the difficulty that the literal translation of that word could hardly serve solely as the title of the English version; he has wisely chosen the word Personality to assist in better expressing the field which he desires his journal to occupy.

The diffictilty is not merely one more illustration of the problems that confront every conscientious translator, but is also symptonatic of the state of that field of study which the title of the journal seeks to indicate. It is a field of which every man has some knowledge and in which every intelligent person is interested; it is one to which great intellects have made their contributions in all ages since the dawn of science; and it is one which has been very actively cultivated in the present century; yet it is one in which there is still the greatest diversity of opinion and in which hardly any conclusions have been generally accepted. Extreme vagueness and uncertainty of terminology is at once a consequence or expression and a continuing cause of this lack of agreed conclusions. We seem to be at a deadlock: we cannot advance to agreed conclusions for lack of common terninology; and we cannot achieve such a terminology because of the extreme diversity of views among authorities.

How may this difficulty be overcome? If a dictatorship or a supreme council were possible and otherwise desirable, we could not look to it to clarify our terminology and fix the meanings of the principal words to be used by workers in this field. Agreement, clarity, and constancy in the meaning of the words can come only gradually, as we progress towards clearer understanding of the complexities of human nature. The best we can do at present is to ac- 
quaint ourselves with the different meanings attached to the same words and, by so doing, fortify ourselves against confusions and misunderstandings arising from this source, and against ambiguity in our own usage of the words. In this short article, then, I propose to try to define clearly some of these differences of meanings.

Of all these differences, that between the German word 'Charakter' and the English 'character,' as used in scientific discourse, is perhaps the most interesting and important. I myself have only in late years clearly realized it; and, for that reason, an the more inclined to think that some discussion of it may be of service.

Charakter, as used in the title of the German version of this journal and as it is most commonly used in German scientific discourse, may, I think, be defined as the sum total of those features, properties, or qualities of an individual organism (or of a species or other natural group) which are peculiar to it and serve to distinguish it from other individuals, species, or groups. Such distinctive features are themselves called 'characters'; therefore we may say that the Charakter of an individual (species or other group) is the sum of its characters. In English the word 'character' is more commonly used to imply the single distinctive feature rather than the sum total of such features. Yet we do use it in both senses. For example we speak of the transmission of acquired characters, here clearly meaning particular distinctive features acquired by individuals. And though biologists do not commonly speak of the character of an animal or of a species or genus, yet common speech recognizes this usage: as when we say that a house, or a tree, or a mountain is full of character or has much character. We use the word in this sense both of individuals and of classes: for example, we may say of the cedar of Lebanon as a species that it has much character; or we may say the same of a single tree of the species, notably of one which displays in accentuated form the features distinctive of the species. In this sense of the word 'character,' it is the achievement of a good caricature to bring out clearly the character of the individual (or group) by accentuating its characters.

These, then, are two closely connected meanings of the word 'character' as used by biologists; and in biology there is little or no difference between tho German and English usage of the word. But among writers who discuss human nature a divergence has arisen: most German writers adhere to the biologists' usage of the word; while English writers use the word in a more specialized sense, in 
accordance with the special meaning of the word prevalent in common speech and literary usage.

That English common speech and literature, in discussing human beings, do use the word 'character' in a sense different from the biologists', and indeed in a very special and pectliar sense, seems clear. But when we seek to define this sense we confront a difficult task. There is pretty close agreement as to the ways in which character* finds expression or reveals itself in conduct. But if we ask-What is that thing named character which thus reveals itself? -we may search the vast literature of the subject and find that few of the atthors get so far as to formulate this question, while fewer still return any answer to it, and no two of these few are in close agreement. Yet all agree that the formation or growth of character is supremely important, and that on our success in the guidance of this process in the young depends the future of our civilization. And how may we hope to suceed in guiding the formation of character, if we have not even the vaguest notion, and no agreement among atthorities, as to the nuture of character in itself; as to how it grows; as to what it is that grows and takes shape and reveals itself in conduct; and as to the nature of the growth processes and how they are affected by external influences?

The modern tendency, especially in America, is to concentrate effort on the study of the expressions of character, while avoiding or neglecting all endeavor to understand what character is. It is, perhaps, legitimate to hope that, when the expressions of character shall have been intensively studied, we shall be able to define character as that which expresses itself in this and that and the other way. And that sort of definition has long been customary. It is generally agreed that character is closely connected with volition; that resolt1tion, decisiveness, consistency, sustained effort in the face of difficulties, the preferring of remoter but greater goods to those that are nearer but slighter, that each and all of these modes of conduct express character.

But such definitions in terms of expressions of character in conduct do not suffice for our practical needs. For our great practical need is to know how character grows, in order that the growthprocess may be forwarded and may be shielded against perverting distorting influences.

$*$ Where this special English meaning of the word is implied I shall print it
in italics. 
There is some agreement as to the course of the growth process. It is agreed that character is in the main formed by gradual growth rather than inborn; that it grows through activity, through effort, through taking responsibility, through the making of hard choices; and that the growth-process is liable to be greatly affected by per. sonal or social influences. Further it is agreed that the growth of character brings with it an increasing integration, an integration that manifests itself, among other ways, in resistance to the various influences to which neurotic disorders of many kinds are due. Finally, it is agreed that character may properly be distinguished from intellect; that, while character and intellect grow side by side and reciprocally infuence one another, the two growth-processes and the resulting organizations are largely independent of one another.

Let us notice at once that, though the German word 'Charakter' is more commonly used in the sense of the biologists, nevertheless, some eminent German authors have used it in a sense closely approximating to this English sense. To go no further back than Kant, we find him writing: "Simply to be able to say of a man: 'he has character' is not only to say a great deal of him, but also to extol him; for that is a rare attribute, which calls forth respect and admira. tion for him."1

Alongside this we may place the fanous dictum of Goethe: "Es bildet ein Talent sich in der Stille, Sich ein Charakter in dem Strom der Welt." The same hand wrote: "The chief mark of character is decisive volition withotit regard to right or wrong, good or evil, truth or error."'2

It is clear that for neither of these great thinkers was Charakter merely any one distinguishing peculiarity or any sum of such peculiarities. For both of them, the word would seem to have carried something of that special meaning of the English word which we have touched on above. Yet, in spite of these leadings, the biological meaning seems to have held the field in German usage and to have well-nigh excluded the more special meaning.

And, though the special meaning has long been well-established in English usage, English psychologists have been slow to accept the challenge of that usage and to attempt any theory of character and its formation, any theory of that part of the total personality which manifests itself in decisive, sustained and integrated effort.

"Cited after Dr. A. A. Roback's Psychology of Character, N. Y., 1927.

"Cited from Dr. L. Klages' "Persönlichkeit," Potsdam, 1927. 
The main ground of this neglect was the predominance of the association psychology; and, no doubt, Herbart's psychology played a similar rôle in Germany; for in both systems the mind was described as a mass or system of ideas, a description which left no room for the distinction between character and intellect.

By the English psychologists character was tacitly left to the moral philosophers. Yet it was a psychologist of the association school, J. S. Mill, who recognized that, when the association principle has done its perfect work of making all the processes of the mind "as plain as the road from Ludgate Circus to St. Paul's Cathedral" (in the words of his father, James Mill) character remains outside the picture, undescribed, unexplained, nay even unmentioned, and yet, as the educators have repeatedly told us, something which, from their point of view, is of far higher importance than intellect. And John Mill was so keenly conscious of this defect of the psychology he championed that he proposed the creation of a new science, Ethology, a science of character, to take its place alongside of psychology, the science of ideas or of intellect. ${ }^{3}$ This proposal had the single merit of pointing to the grave defect of a psychology that ignored the problem of character; and Mill's great prestige, though it secured a respectful hearing for this proposal, postponed the much needed reform of psychology by countenancing the continued exclusion from it of the problem of character.

The proposal to create an independent science of character was renewed, independently and nearly two generations later, by another eminent English psychologist, Charles Mercier (who, however, would have had it called 'praxiology'), a fact which surely indicates that Mill's proposal, having failed to bear fruit during two generations, was seriously at fault.

The only British psychologist during the nineteenth century to go beyond the definition of character in terms of its manifestations and to make a serious attempt at a theory of character was Alexander Bain;" but, as Dr. Roback justly observes, "On the whole his position is too much that of the phrenologists in that he includes under character the most miscellaneous things, such as virtues, abilities, emotions, and general tendencies-all mixed promiscuously in one grand potpourri."

Various French writers throughout the nineteenth century ren-

'In his Logic (1843).

* The Study of Character (1861). 
dered, with literary skill and charm, descriptions of characters or, as we should say in English, of personalties, and attempted to classify them. But they were not using the word 'character' in the special English sense, a fact made clear by Ribot's essay on the diverse forms of character (1892) in which he reached the conclusion. that character is innate.

In $1896 \mathrm{Mr}$. A. F. Shand ptiblished an articles in which he discussed the nature of sentiments of various types, especially love, hate, and respect, and pointed to them as the principal constituents of character. This essay may justly be awarded the credit of having made the first step towards a theory of character. Prof. G. F, Stout made the next step by clarifying the conception of the sentiment in a single short paragraph of his Manual of Psychology. ${ }^{6} \mathrm{He}$ has, however, very little to say of character. IYe defines it thus: "Character is just the constitution of the Self as a whole;" a definition which leaves 'character' synonymous with 'personality.' Yet in the next sentence he does seem to use 'character' in the special Eng. lish sense; for it runs: "Character exists only in so far as unity and continuity of conscious life exists and manifests itself in systematic consistency of conduct."

Seizing on the clues afforded by Shands' article and Stout's few but extraordinarily trenchant and clarifying observations on the sentiments, I developed in my Social Psychology the theory of the sentiments and of their integration into a system which is character. Such an integrated system, I arguted, is achieved by an hierarchical organization of the sentiments under the dominance of some one master-sentiment, the dominant rôle being filled most commonly and most effectively by the sentiment of self-regard or self-esteen.

In 1914 Shand published his Foundations of Character. In that book he is chiefly concerned with discovering the laws of the sentiments and with displaying the sentiments as the source of types of

- Character and the Emotions, Mind, N. S. No. 18.

- The essential passage runs: "Such words as liking and disliking, hate and love, indicate emotional dispositions rather than actual emotions. We say that the cat dislikes the child, meaning, not that it is actually fecling angry with the child at the moment, but that it has a permanent tendency to feel the emotion of anger whenever it sees the child in its neighbourhood. On the higher levels of mental life, where ideas and concepts play a prominent part, emotional dis. positions are very complex, and are called Sentiments or Interests."

"London, 1908. The scheme is stated more concisely and concretely and, perhaps, more effectively in a chapter on The Structure of Character appended to the twenty-first English edition of the book, and more popularly in my Character and the Conduct of Life, London and N. Y., 1927. 
character. He nowhere attempts any concise definition of character, but aims, rather, gradually to unfold his conception of it; yet that he uses the word in the traditional English sense is clear. "Our conduct is the effect and expression of our character." But character "is not constituted of the emotions and sentiments alone with the will and intelligence as their instruments. It has other and very numerous and important constituents." These other constituents remain somewhat nebulous. Yet Shand is not guilty of following Bain in making of character 'one grand potpourri.' He has the great merit not only of insisting on the growth of the sentiments and on their central place in character, but also of distinguishing clearly between, on the one hand, character and, on the other hand, temperament and temper.

The theory of character thus sketched in outline has gained wide acceptance among British psychologists. There is a considerable number who, while differing on details, agree in respect of the following points :

(1) that the character of a man is, not the whole, but a part only of his total personality;

(2) that character is to be broadly distinguished from intellect, as a complementary side of developed personality;

(3) that character is not innate, but rather is a product of gradual individual development; that, as Goethe said, it is formed by taking part in the stream of the world, in the battle of life;

(4) that character is a highly complex organization or structure, the units of which are the sentiments, the enduring likes and dislikes, the loves and hates, the admirations, respects, and contempts which every man acquires for a large number of objects (for persons, for concrete things, for general and for abstract objects);

(5) that the mere possession of sentiments (even though they be many and strong) does not in itself constitute character;

(6) that, rather, character is achieved by each man only in so far as his sentiments become organised in a stably integrated system within which they operate and coöperate with some degree of harmony;

(7) that individuals progress to very various stages and forms of integration of the system of sentiments;

(8) that, since the possible forms of sentiment are very numerous and since the possible objects of sentiments are "all the choir of heaven and furniture of earth," and since the forms and degrees 
of integration of the system of sentiments are various, any attempt to classify the characters of men under a few types is doomed to futility;

(9) that character, although it may be validly distinguished from intellect, cannot be profitably sundered from it in the way implied by all proposals to make it the object of a special science in any degree distinct from, or independent of, psychology, the way inplied by such terms as ethology, praxiology, characterology, and science of character.

This, then, is the English contribution towards the understanding of character: first, the popular mind, guided by men of letters and the moral philosophers, formed a special conception of character as that part of personality which is specially concerned in action, which manifests itself most clearly in the higher forms of volition, and which is gradually developed in and through social intercourse, Secondly, the psychologists have evolved the outline of a theory of character, of its constituent parts, of their formation, and of their integration to form an organized system.

It is a striking fact that, in spite of all our modern facilities of intercourse, this conception and this theory of character remains peculiarly and almost exclusively British. In spite of the lead in the same direction given by Kant and Goethe, very few German students have followed along this line. Of these, Dr. Ludwig Klages, seemingly in complete detachment from the English tradition, has arrived at a theory of character which, in spite of certain metaphysical assumptions (concerning Geist and Wille) that make his Charakterologie quite distinctive, is in some respects allied to the English theory. Tis theory of character includes a system of driv. ing forces; these forces are described as Interessen or Trieb-federn; as illustrations of such driving forces are mentioned ambition, lust for power, love of glory, self-esteem; and it seems clear that these central constituents of character correspond pretty closely to the sentiments of the English authors. But Klages includes much else in his conception of Charakter. For example, his chapter on "The Nature, Structure and Material of Character"s begins thus: "From the innumerable traits of character which have been fixed in language we take four at hazard: sense of gain; sense of duty; talent for music; memory." Further, he tells us that the totality of talents is the material of character; the totality of interests (Tricbfedern or

${ }^{8}$ I cite from the English translation of his Science of Chatacter, London, 1928, Cambridge, Mass. 1932. Sci-Art Publishers. 
Interessen) is the nature of character; while the totality of dispositions governing the course of emotions is the structure of character. And a further chapter entitled "The Structure of Character" is largely devoted to a discussion of temperament. From these and other statements it seems clear that Klages uses 'Charakter' in the general biological sense rather than in the special English sense; that for him the Charakter of any individual is the sum total of traits that distinguish him from others; that his affinity with the English theory of character consists in his recognition of the Triebfedern as organized units of a higher order than the urges or impulses (die Triebe) of animals, and of the fact that these units (the sentiments of English authors) become organized in some kind of system. For Klages, then, the word Charakter is synonymous or very nearly so with Persönlichkeit, as $\mathrm{D}_{1}$. Prinzhorn points out in his recent very excellent review ${ }^{9}$ of all this field; an interpretation confirmed by the fact that Klages has published, under the title Persönlichkeit Einfiihrung in die Charakterkunde, ${ }^{10}$ a condensed version of his doctrine of Charakter.

Since Klages and Prinzhorn are the two German contemporaries who recognize more adequately than any others that part of personality which is implied by the English word 'character' and since they continue to use Charakter as equivalent to the total personality (Gesant-persönlichkeit), we see the necessity of translating the Gernan title of this journal (Charakter) by the word 'Personality.' That the German usage will eventually be assimilated to the English by specialization of the word 'Charakter' it would be rash to predict; but it may fairly be claimed that English usage has achieved a useful differentiation of the two words 'personality' and 'character.'11

Among contemporary French psychologists one only seems to have distinguished within the total personality the part implied by the English theory of character. In his later writings Dr. Pierre Janet has had much to say of dynamic tendencies; he has described

"Charakterkunde der Gegenwart, Berlin, 1931.

${ }_{10}$ Potsdam, 1927.

${ }^{11}$ It would be improper to omit mention of Dr. William Stern's treatment of 'Charakter' in his Menschliche Persönlichkeit, which reveals some affinities with the English theory. It is well summarised by Roback as follows: "Conation, as with the British psychologists, holds a foremost place in the dispositions of man. These he divides into (a) directive and (b) auxiliary tendencies which are always ready to serve the former. Character, according to Stern, is the unit of all the directive dispositions of a person." 
them as being formed and becoming organized in an integrated hierarchy; and at the head of this hierarchy he places, curiously enough, as the supreme integrating factor, a tendency which he calls the work-tendency. Here clearly is an architectonic system not unlike in its widest features the integrated system of the sentiments.

In America the situation is peculiar. Undoubtedly the moralists and the educators and popular speech use the word 'character' if the English sense. ${ }^{12}$ But the psychologists have hardly begun to attempt a theory of character. Y $Y$ ct the beginnings are there. In Prof. Woodworth's Psychology, the most widely used I suppose of all American texts, I find only two sentences concerning character. One speaks of steps "in organizing the individtal's reaction-tenden. cies into what we call his character - the more or less organized sum total of his native and acqutired tendencies to reaction, with em. phasis on those reactions that affect his life and social relations in a broad way." The other sentence tells us that stuclies of the rulers of Europe "show that on the whole those with higher intelligence were also of better character and personality." In the same work Woodworth also says a few words on integration. "We may speak of one person as being well integrated, meaning that he is always himself, his various tendencies being so coördinated as to work reasonably well together; whereas, of another we speak as poorly integrated, unstable, an uncertain quantity. Integration is achieved partly by selection from among conflicting impulses, partly by co. ordination, partly by judicious treatment of those impulses that are denied." But I find no mention of the sentiments, and no de. scription of them under any head. They are as conspicuous by their absence as in William James's great Principles.

During the thirty years that separate these two leading texts, the theory of the sentiments fotnd no foothold in America. It is true that the social psychologists have in the last few years busied them. selves with questionnaires on what they call 'social attitudes.' And at first it might seem as though 'social attitude' were another name for a sentiment. But a closer inspection of the literature ${ }^{13}$ shows

Out of a multitude of illustrations I choose the most recent. Dr. W. G. O'Shea, superintendent of the schools of New York, is reported in the New York Times (May 31, 1932) to have said "Character development is the great, if not the sole, aim of the school." In this dictum, summarizing an eloquent or:tion which emphasized the qualities of the heart over against those of the intellect, 'character' clearly is used in the special English sense.

${ }^{13}$ Cf. Especially Social Attitudes by several authors edited by Kimball Young (N. Y., 1930) and also section on the same topic in Gardner Murphy's Experimental
Social Psychology, N. Y, 1931. 
that the term as commonly used includes opinions, beliefs, prejudices, preferences, tastes, traits, qualities of all sorts, in fact almost anything that can be elicited by means of a questionnaire. It may be suspected that somewhere in this potpourri lurk the sentiments, and that eventually they may crystallize out of the highly complex magma. But it is clear that, as at present used, 'social attitude' is a term that can contribute little towards a theory of character.

There has been considerable effort to devise methods of measuring traits of character; but, as with the similar work of Webb in England, one feels that some outline of a theory of character is needed for the guidance of such work, and that, without such guidance, the experimental approach to character is wandering in a wilderness.

The learned author of The Psychology of Character, Dr. A. A. Roback, avoids the confusion of character with temperament and uses the word to point to "an integral part of personality-a definite integration, the result of innate dispositions and acquired tendencies." Defining character as "the psycho-physical disposition to inhibit instinctive tendencies in keeping with fundamental principles of action," he regards inhibition of instinctive urges as the essential mark, measure, and function of character. It is clear, then, that he uses the word 'character' in the special English sense, though laying special emphasis on the inhibition which is one aspect of all volitional activity. But he cannot be claimed as an exponent of the English theory of character. Instead of seeking the explanation of control in an integrated hierarchy of sentiments working according to the principle of configuration, he postulates two special controlling agencies : first, an innate 'consistency urge'; secondly, undefined 'regulative principles.' As regards the latter he leaves us very much in the dark, contenting himself with the cryptic remark that these allimportant principles "claim as their psychological basis a mechanism yet to be investigated."

It is true that in a few brief sentences he recognizes the sentiments; and he even says of his 'regulative principles' that "they may be regarded as sentiments, that is to say, affective complexes"; yet they "are more logical than psychological, inasmuch as they attach to cognition rather than to affection or instinct."

$\mathrm{Up}_{\mathrm{p}}$ to this point $\mathrm{I}$ have been concerned to make clear the difference between the German 'Charakter' and the English 'character' and have by implication put in a plea for the more specialized Eng- 
lish usage which differentiates character from personality as a part from the whole.

I add a few words on the use of the word 'temperament.' Here the prevailing uncertainty and confusion of usage are even greater. The ancients gave us a definition and a theory of temperament which seem to have been on essentially right lines. It might have been hoped that, with this strong lead, modern writers would achieve some measure of agreement and consistency in the use of the word. Most of those who have discussed temperament fall into two classes: first, those who follow the classical doctrine of the four temperaments with superstitious exactitude or with some slight modification; secondly, those who frankly make 'temperament' synonymous with 'character.' There are also some few who combine these practices, regarding the ancient doctrine of the four temperaments as the last word on character.

The late Dr. Charles Mercier, eninent as psychiatrist, psychologist, and logician, and a careful writer, gave to one of his books the title Human Temperament, Studies in Character, thus frankly disclaiming all attempt to differentiate the two words. And many others have followed his example in this matter. Are we, then, to be content to use the three words 'personality.' 'character,' and 'temperament' as synonymous? Surely not! To do so would be a confession of intellectual sloth. Here are three words which in poptlar and literary usage are differentiated, though allied, in meaning. Can psychologists do no better than to confuse and obscure these useful differentiations?

The classical doctrine ascribed peculiarities of temperament to the 'humors' of the body. Modern science has shown those 'humors' to be more numerous, more powerful, and more various in their influence upon the life of the whole organism, upon personality, than the ancients had supposed. Why, then, in the light of this modern knowledge, should we not piously preserve what was true in the classical doctrine, namely, the truth that the chemistry of the blood profoundly influences our mental life, determining our temperamental peculiarities, while frankly recognizing that the particular form taken by the classical doctrine (that of the four temperaments) was utterly wrong. In place of the bile, the blood, the choler, and the phlegm, as the sole determinants of temperament, let us put: the many chemical substances, especially the hormones, now known 
to affect profoundly the working of the nervous system and the whole organism.

Temperament thus conceived is in no danger of being confused with character by those who recognize character in the English sense of the word. Under this view, temperament may be called an inner environment of character, a highly complex environment which may profoundly influence the working of character without changing the structure of character. Illustrations of this relation are familiar. Disease and drugs, modifying the chemistry of the body, can profoundly modify temperament, while leaving character essentially unchanged. During the prevalence of some unusual chemical influence the extent to which character reveals itself may be modified; but on the passing away of that chemical influence (i.e. on the restoration of the normal conjunction of temperamental factors) the character manifests itself as before. The most familiar illustrations are afforded by fatigue and alcohol. Either of these chemical factors does (in proportion to the quantity present in the blood) modify for the time being the temperament; and in either case, under the changed inner environment, the man's character functions in abnormal fashion for the time being. But it is merely a matter of the clogging and impairment of the character functions; under both of these influences, the higher functions of character are for the time being impaired and the cruder simpler sentinents function with but little control from that critical self-consciousness which, in the normal state of the personality, is the fly-wheel of the whole system of character. Yet the effect is merely a temporary disturbance; as soon as the internal chemical environment returns to normal, character manifests itself as a stable organization that endures throughout all such temperamental variations.

If, then, character is to be regarded as a part only, rather than as the whole, of personality; and if temperament is the sum of the influences of the internal chemical environment, what are the other constituents of personality? I have suggested elsewhere ${ }^{\mathbf{1 4}}$ that personality may with advantage be broadly analyzed into five distinguishable but inseparable factors, namely, intellect, character, temperament, disposition, and temper. If we recognize that each of these is highly complex, that each comprizes many independent variables, that each word is a heading under which we classify

14 "The Chemical Theory of Temperament applied to Introversion and Extroversion," Journal of Abnormal and Social Psychology, 1929. 
a multitude of factors of allied nature, we shall be preserved from wasting further energy in the futile search for some limited number (be it two, four, eight, sixteen, or six) of well defined types of personality. We shall understand more fully that personalities are infinitely various and complex; and that yet each personality is in its degree an integrated unity of all its factors, a unity which in action exemplifies the principle of configuration, a system of energies, each distinguishable part of which owes something of its nature to its place in the whole and to its active relations with all other parts.

Received June 15, 1932. 